\title{
Dose response relationship of cumulative anticholinergic exposure with incident dementia: validation study of Korean anticholinergic burden scale
}

Yewon Suh ${ }^{1,2+}$, Young-Mi Ah ${ }^{3+}$, Euna Han ${ }^{4}$, Kwanghee Jun ${ }^{1}$, Sunghee Hwang ${ }^{5}$, Kyung Hee Choi ${ }^{6}$ and Ju-Yeun Lee ${ }^{1 *}$ (D)

\begin{abstract}
Background: The dose response relationship of nine-year cumulative anticholinergic exposure and dementia onset was investigated using the Korean version anticholinergic burden scale (KABS) in comparison with the Anticholinergic Cognitive Burden Scale (ACB). We also examined the effect of weak anticholinergics in the prediction of dementia.

Methods: A retrospective case-control study was conducted comprising 86,576 patients after 1:2 propensity score matching using the longitudinal national claims database. For cumulative anticholinergic burden estimation, average daily anticholinergic burden score during the 9 years prior to dementia onset was calculated using KABS and ACB and categorized as minimal, <0.25; low, 0.25-1; intermediate, 1-2; and high, $\geq 2$. Adjusted odds ratio (aOR) between cumulative anticholinergic burden and incident dementia was estimated.

Results: Patients with high exposure according to KABS and ACB comprised 3.2 and $3.4 \%$ of the dementia cohort and 2.1 and $2.8 \%$ of the non-dementia cohort, respectively. Dose-response relationships were observed between anticholinergic burden and incident dementia. After adjusting covariates, compared with minimal exposure, patients with high exposure according to KABS and ACB had a significantly higher risk for incident dementia with aOR of 1.71 (95\% confidence interval (CI) 1.55-1.87) and 1.22 (Cl 1.12-1.33), respectively. With the exclusion of weak anticholinergics, the association became stronger, i.e., 1.41 (Cl 1.14-1.75) with ACB whereas the association became slightly weaker with KABS, i.e., 1.60 (Cl 1.38-1.86).
\end{abstract}

Conclusion: This study confirmed the dose response relationship for cumulative anticholinergic burden measured using the Korean specific anticholinergic burden scale with incident dementia.

Keywords: Aged, Anticholinergic agents, Anticholinergic burden scale, Dementia

\footnotetext{
* Correspondence: jypharm@snu.ac.kr

†Yewon Suh and Young-Mi Ah contributed equally to this work.

'College of Pharmacy and Research Institute of Pharmaceutical Sciences,

Seoul National University, 1 Gwanak-ro, Gwanak-gu, Seoul 08826, Republic of

Korea

Full list of author information is available at the end of the article
}

C C The Author(s). 2020 Open Access This article is licensed under a Creative Commons Attribution 4.0 International License, which permits use, sharing, adaptation, distribution and reproduction in any medium or format, as long as you give appropriate credit to the original author(s) and the source, provide a link to the Creative Commons licence, and indicate if changes were made. The images or other third party material in this article are included in the article's Creative Commons licence, unless indicated otherwise in a credit line to the material. If material is not included in the article's Creative Commons licence and your intended use is not permitted by statutory regulation or exceeds the permitted use, you will need to obtain permission directly from the copyright holder. To view a copy of this licence, visit http://creativecommons.org/licenses/by/4.0/ The Creative Commons Public Domain Dedication waiver (http://creativecommons.org/publicdomain/zero/1.0/) applies to the data made available in this article, unless otherwise stated in a credit line to the data. 


\section{Background}

Dementia, especially Alzheimer's disease, is caused by a combination of ageing, genetic, health, environmental, and lifestyle factors. There is a great deal of interest in identifying the modifiable risk factors of cognitive decline and dementia [1]. Previous studies suggested that the use of medications such as anticholinergics is related to worsening of cognitive functions or incidence of dementia [2, 3]. Several tools for measuring anticholinergic burden, the summed effect of multiple medications with various anticholinergic potency, have been developed to predict the potential adverse outcome of anticholinergic use. The Anticholinergic Cognitive Burden Scale (ACB), Anticholinergic Drug Scale (ADS), and Anticholinergic Risk Scale (ARS) are the three most popular tools [4]. The advantage of these tools over lists of strong anticholinergics might be that they allow the summation of unrecognized medications with weak anticholinergic effects as well as strong anticholinergics for measuring the anticholinergic burden [5].

However, previously developed tools cannot be directly applied to practice in other countries because medication availability differs considerably, and considerable inconsistencies exist among the tools regarding the listed medications and their anticholinergic potency scores. Therefore, the Korean version anticholinergic burden scale (KABS) was developed using the Delphi methods after reviewing previous scales for the medications having discordant scores among scales and for the newly added medications that have been available in Korea but have not been reviewed [6].

The longitudinal effect of anticholinergics on incident dementia or cognitive impairment has been investigated in several studies with controversial results [2, 7-12]. Some studies defined the exposure of anticholinergics with the continued or cumulative use of strong anticholinergics without considering the anticholinergic score $[2,7,8,11]$. However, only a few studies used the anticholinergic burden scale which includes both the strong and the weak anticholinergics with the scoring system. Richardson et al. [9] examined the association between anticholinergic burden assessed with the ACB scale and dementia risk using a nested case-control study in the UK. Hsu et al. [10] showed a dose response relationship of anticholinergic burden measured with ARS, ACB, and Drug Burden Index-Anticholinergics with incident dementia as one of the adverse outcomes using Taiwan's National Health Insurance data.

We hypothesized that a greater cumulative anticholinergic exposure measured using the burden scale increases the risk of incident dementia and that the KABS, consensus-driven, Korea specific anticholinergic burden scale, will outperform the tool developed from other countries in predicting the risk of dementia in the
Korean population. We aimed to evaluate the validity of KABS in comparison with that of the ACB scale by investigating the association between nine-year cumulative anticholinergic exposure and dementia using the longitudinal nationally representative cohort comprising the elderly population. In addition, we also aimed to investigate whether the inclusion of weak anticholinergics in measuring anticholinergic burden influences the prediction of dementia.

\section{Method \\ Study population and database}

A longitudinal database was used for this case control study, the Korea National Health Insurance Service Senior Cohort database (2002-2013) that was developed and provided by the Korea National Health Insurance Service, a single and mandatory national insurance service. This database comprised 558,147 patients over 60 years, representing $10 \%$ of the Korean senior population. Its representativeness was supported by the results of a study comparing this database with population statistics based on resident registration, Statistics Korea's data of December 2013 [13].

Older adults with no diagnosis of dementia during the prior years of 2002-2011 and alive as on January 1, 2013, were initially selected from the Korea National Health Insurance Service Senior Cohort database. Among them, patients who were diagnosed with dementia (either vascular or Alzheimer's or both; ICD-10 codes: F00, F01, F02, F03, F051, G30, and G311) in 2012-2013 were selected. Index dates were defined as the earliest date of claims with the diagnostic code for dementia. Control cohorts were selected among the patients without dementia after propensity score matching. Details are described in statistical analysis.

\section{Measure of anticholinergic burden}

Exposure to anticholinergic drugs was measured during the nine prior years starting 10 years before the index date and ending 1 year before the index date. Drug exposure in the recent one-year period was excluded to minimize the protopathic bias. Nine-year cumulative drug exposure was measured in all patients (Fig. 1). The anticholinergic burden for each patient was assessed using KABS and ACB (Additional file 1). Both scales assigned 1 for mild, 2 for moderate, and 3 for strong anticholinergics. First, the standard daily dose was calculated with the prescribed dose for each medication divided by the defined daily dose (DDD) of the World Health Organization. Then, we summed the standard daily dose for anticholinergic drugs after multiplying the assigned anticholinergic score during the period of drug exposure. This method was modified from that suggested by Gray et al. [8] with multiplying the 


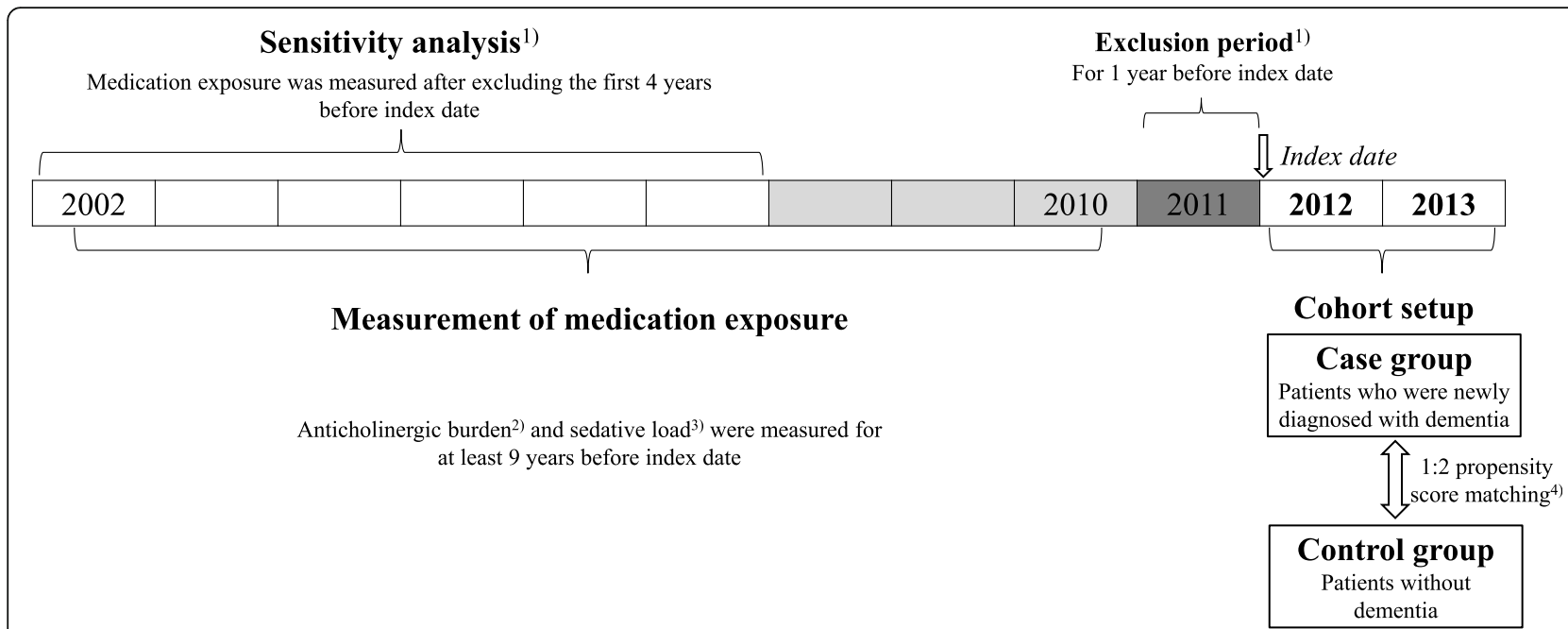

Fig. 1 The layout of research design. ${ }^{1)}$ In order to minimize the protopathic bias, the first year before index date was excluded. Also, sensitivity analysis was done after excluding the first 4 years before index date. ${ }^{2)}$ The Korean version anticholinergic burden scale (KABS) and the Anticholinergic Cognitive Burden Scale (ACB) were used as the standard of anticholinergic burden score. ${ }^{3)}$ For measuring the sedative load, the sedative load model was used; score 2 for primary sedative agents and score 1 for medications having sedation as a prominent side effects. ${ }^{4)}$ Matching variables: age, sex, and baseline co-morbid diseases including hypertension, dyslipidemia, heart failure, atrial fibrillation, ischemic heart disease, diabetes mellitus,

cerebrovascular disease, Parkinson's disease, depression, anxiety, insomnia, and alcohol disease

anticholinergic score assigned by each anticholinergic burden scale. We finally calculated the average daily anticholinergic burden score during the drug exposure period. We categorized the anticholinergic burden according to daily average score as follows: $<0.25$, minimal exposure; $0.25-1$, low exposure; $1-2$, intermediate exposure; and $\geq 2$, high exposure. We further investigated the anticholinergic drugs most contributing to high exposure prior to the index date in patients with dementia according to $\mathrm{KABS}$ or $\mathrm{ACB}$.

\section{Covariates}

As confounders that might affect the onset of dementia, we selected baseline comorbid diseases such as hypertension, dyslipidemia, heart failure, atrial fibrillation, ischemic heart disease, diabetes mellitus, cerebrovascular disease, Parkinson's disease, depression, anxiety, schizophrenia, bipolar disorder, insomnia, alcohol disease, obesity, substance abuse, and tobacco dependence and use.

These comorbid diseases were identified when there were two or more claims with the relevant diagnostic code (Additional file 2) before January 1, 2012. For covariates, the sedative load during the same period was calculated. We used the sedative load model for measuring the sedative load, which assigned 2 for the primary sedative and 1 for medications having sedation as a prominent side effect. We excluded the medications that were assigned 1 or a higher anticholinergic score by each scale for measuring the sedative load (Additional file 3).

\section{Statistical analysis}

To reduce the effect of confounding factors, control cohorts were selected using the propensity score matching method with the ratio of 1:2 using variables including age, sex, and baseline comorbid diseases that are known to cause of dementia including hypertension, dyslipidemia, heart failure, atrial fibrillation, ischemic heart disease, diabetes mellitus, cerebrovascular disease, Parkinson's disease, depression, anxiety, insomnia, and alcohol disease. The matching was performed using a greedy algorithm with a caliper width equal to 0.2 standard deviations of the logit of the propensity score. The measured anticholinergic burden by both scales was described and compared between the case and control cohorts. We used Chi-square test for comparison of categorical variables for baseline characteristics. Multivariate logistic regression analysis was performed to evaluate the independent association between the anticholinergic burden and the incidence of dementia to adjust for the covariates including age, sex, the baseline co-morbid diseases, and sedative load. Adjusted odds ratios (aOR) with 95\% confidence intervals $(\mathrm{CI})$ are reported.

In the secondary analysis, we also investigated the impact of weak anticholinergic agents on each scale after excluding them. To minimize reverse causation bias, the association between incident dementia and the cumulative anticholinergic burden during the $5-10$ years prior to the index date after excluding the most recent 4 years was analyzed as part of the sensitivity analysis. Data 
management and statistical analysis were performed using SAS version 9.3 (SAS Institute, Inc., Cary, NC, USA).

\section{Results}

\section{Population characteristics}

Among the 558,147 adults aged more than 60 as of 2002 included in the sample senior cohort, 104,087 patients and 137,680 patients were excluded because they were diagnosed with dementia before the year 2012 and because they had not survived until the year 2013, respectively. The total sampled population included 28,864 patients who were diagnosed with dementia between 2012 and 2013. After propensity score matching, 57,712 patients without dementia were identified as the control and in total 86,576 patients were included for the analysis (Fig. 2).

The median age at the time of dementia diagnosis was 79 (inter-quartile range (IQR), 75-83) and women accounted for $69.3 \%$. As the comorbid condition, 79, 61, $49,46,45,39,35$ and $30 \%$ of the patients had hypertension, dyslipidemia, diabetes, anxiety, cerebrovascular disease, insomnia, ischemic heart disease, and depression, respectively (Table 1 ).

\section{Prevalence of anticholinergic burden}

During the $2-10$ years before the index date, $46.2 \%$ of patients with dementia and $50.7 \%$ of patients without dementia were exposed minimally to anticholinergics (average daily KABS score < 0.25). Fewer patients were identified as having intermediate anticholinergic exposure using KABS compared to that using $\mathrm{ACB}$ in both cohorts with dementia (10.6 and $13.7 \%, p<0.01$, respectively) and without dementia (8.9 and $12.9 \%, p<$ 0.01 ). Proportions of patients with high exposure were $2.1 \%$ (for the KABS) and $2.8 \%$ (for the ACB) in the cohort without dementia and $3.2 \%$ (for the KABS) and $3.4 \%$ (for the ACB) in the cohort with dementia (Table 2).

\section{Major anticholinergic drugs}

The top 20 anticholinergic drugs that most contributed to high exposure prior to the index date in patients with dementia according to KABS and ACB are presented in Table 3. Cimetidine, dimenhydrinate, chlorpheniramine, furosemide, and diazepam contributed the most to the total KABS score, while dimenhydrinate, hydrochlorothiazide, isosorbide, chlorpheniramine, and nifedipine contributed most to the total ACB score in patients with dementia with high exposure. Drugs with a KABS score of 3,2 , and 1 contributed $47.4,19.3$, and $33.3 \%$, respectively, to the cumulative amount of the KABS score, whereas those with an ACB score of 3,2 , and 1 contributed $41.4,1.8$, and $56.7 \%$, respectively, to the cumulative amount of the ACB score in dementia patients with high exposure.

\section{Association between anticholinergic burden and incident dementia}

There were significant associations between incident dementia and nine-year cumulative dose adjusted anticholinergic burden of low, intermediate, and high exposure compared with that of minimal exposure assessed by KABS with corresponding aOR of 1.21 (95\%

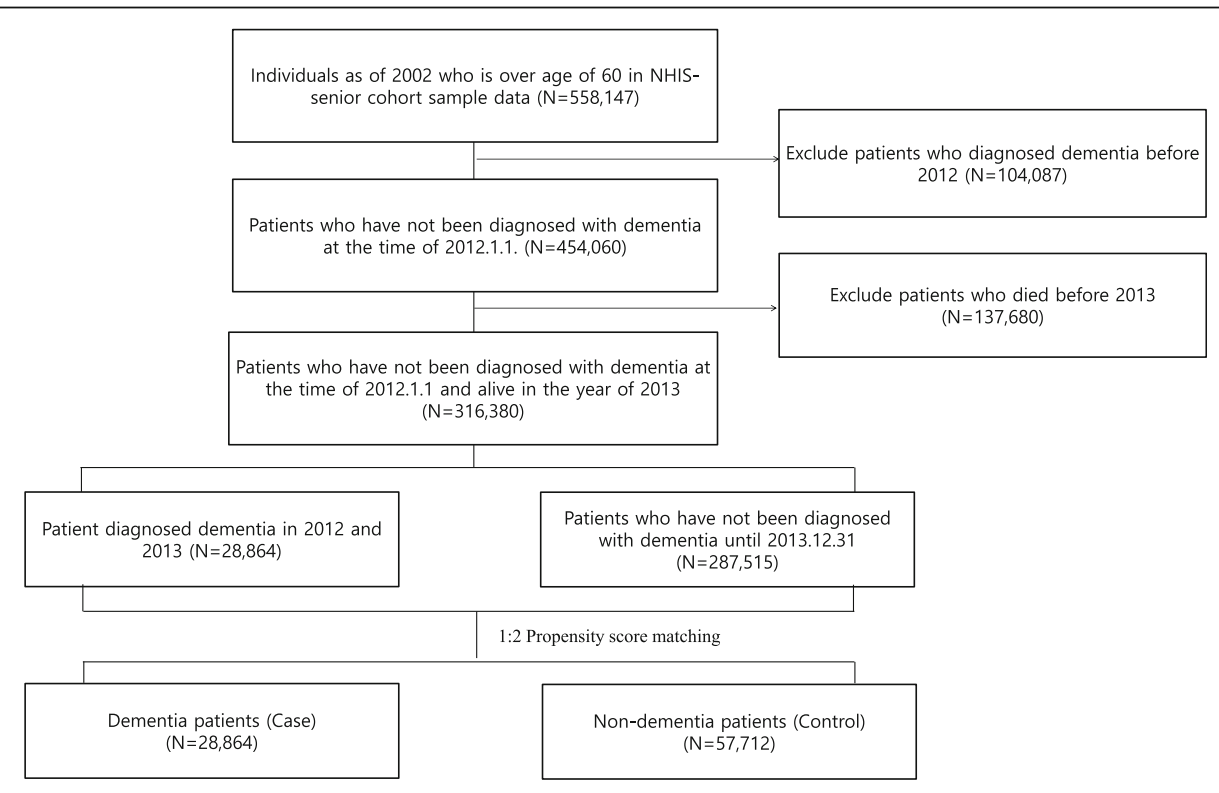

Fig. 2 Flow chart for selecting patients. NHIS; National Health Insurance Service 
Table 1 Demographic data of patients with and without dementia before and after propensity score matching

\begin{tabular}{|c|c|c|c|c|c|c|}
\hline & \multicolumn{2}{|l|}{ Before matching } & \multirow[b]{2}{*}{$\boldsymbol{p}$-value } & \multicolumn{2}{|l|}{ After matching } & \multirow[b]{2}{*}{$\boldsymbol{p}$-value } \\
\hline & $\begin{array}{l}\text { Non-Dementia } \\
(\boldsymbol{N}=287,515)\end{array}$ & $\begin{array}{l}\text { Dementia } \\
(\boldsymbol{N}=28,865)\end{array}$ & & $\begin{array}{l}\text { Non-Dementia } \\
(\boldsymbol{N}=57,712)\end{array}$ & $\begin{array}{l}\text { Dementia } \\
(\boldsymbol{N}=28,864)\end{array}$ & \\
\hline Age, median (IQR) & $76(73 \sim 80)$ & $79(75 \sim 93)$ & & $79(75-83)$ & $79(75-83)$ & \\
\hline $70-80$ years & $214,874(74.7)$ & $15,894(55.1)$ & $<0.001$ & $31,621(54.8)$ & $15,894(55.1)$ & 0.400 \\
\hline 80-90 years & $65,342(22.7)$ & $11,041(38.2)$ & & 22,098 (38.3) & $11,041(38.3)$ & \\
\hline$\geq 90$ years & $7,299(2.6)$ & $1,930(6.7)$ & & $3,993(6.9)$ & $1,929(6.7)$ & \\
\hline Sex, female & $170,007(59.1)$ & $20,005(69.3)$ & $<0.001$ & 40,338 (69.9) & $20,004(69.3)$ & 0.744 \\
\hline \multicolumn{7}{|l|}{ Co-morbid disease } \\
\hline Hypertension & 203,036 (70.6) & $22,848(79.2)$ & $<0.001$ & $46,059(79.8)$ & $22,848(79.2)$ & 0.371 \\
\hline Dyslipidemia & $157,248(54.7)$ & $17,545(60.8)$ & $<0.001$ & $35,262(61.1)$ & $17,545(60.8)$ & 0.761 \\
\hline Ischemic heart disease & $81,060(28.2)$ & $10,123(35.1)$ & $<0.001$ & 20,201 (35.0) & $10,123(35.1)$ & 0.843 \\
\hline Heart failure & $41,404(14.4)$ & $6,266(21.7)$ & $<0.001$ & $12,353(21.4)$ & $6,266(21.7)$ & 0.305 \\
\hline Atrial fibrillation & $10,614(3.7)$ & $1,491(5.2)$ & $<0.001$ & $2,603(4.5)$ & $1,491(5.2)$ & $<0.001$ \\
\hline Diabetes Mellitus & 113,939 (39.6) & $14,113(48.9)$ & $<0.001$ & 28,084 (48.7) & $14,113(48.9)$ & 0.519 \\
\hline Cerebrovascular disease & $76,776(26.7)$ & $12,863(44.6)$ & $<0.001$ & 25,917 (44.9) & $12,863(44.6)$ & 0.338 \\
\hline Depression & $52,179(18.2)$ & 8,555 (29.6) & $<0.001$ & $16,923(29.3)$ & 8,555 (29.6) & 0.336 \\
\hline Bipolar disorder & $2,853(1.0)$ & $540(1.9)$ & $<0.001$ & $889(1.5)$ & $540(1.9)$ & 0.003 \\
\hline Schizophrenia & $1,662(0.6)$ & $354(1.2)$ & $<0.001$ & $460(0.8)$ & $354(1.2)$ & $<0.001$ \\
\hline Anxiety & $97,503(33.9)$ & $13,385(46.4)$ & $<0.001$ & $26,680(46.2)$ & $13,385(46.4)$ & 0.691 \\
\hline Insomnia & $78,382(27.3)$ & $11,320(39.2)$ & $<0.001$ & $22,611(39.2)$ & $11,320(39.2)$ & 0.911 \\
\hline Substance abuse & $1,663(0.6)$ & $307(1.1)$ & $<0.001$ & $498(0.9)$ & $307(1.1)$ & 0.004 \\
\hline Tobacco dependence and Tobacco use & $113(0.0)$ & $15(0.02)$ & 0.308 & $22(0.04)$ & $15(0.02)$ & 0.353 \\
\hline Parkinson's disease & $4,893(1.7)$ & $1,371(4.8)$ & $<0.001$ & $2,305(4.0)$ & $1,371(4.8)$ & $<0.001$ \\
\hline Obesity & $472(0.2)$ & $42(0.2)$ & 0.453 & $97(0.2)$ & $42(0.2)$ & 0.434 \\
\hline Alcohol disease & $1,566(0.5)$ & $280(1.0)$ & $<0.001$ & $467(0.8)$ & $280(1.0)$ & 0.016 \\
\hline
\end{tabular}

IQR Inter-quartile range

CI, 1.17-1.25), 1.39 (95\% CI, 1.31-1.46), and 1.71 (95\% CI, 1.55-1.87), respectively. A similar association was observed when the anticholinergic burden was measured using $\mathrm{ACB}$ but corresponding aORs were lower than those measured using KABS. A high cumulative anticholinergic burden measured using the $\mathrm{ACB}$ was significantly associated with dementia incidence with an aOR of 1.22 (95\% CI, 1.12-1.33) (Table 4).

When the anticholinergic burden was measured after excluding weak anticholinergics $($ score $=1)$, the proportion of patients with low to high anticholinergic exposure was significantly reduced, and this reduction was much greater using the $\mathrm{ACB}$ scale versus that using the KABS. The effect size of the association with incident dementia was similar when exposure was measured using KABS without regard to the inclusion of weak anticholinergics. The KABS scale with weak anticholinergics showed slightly greater association than that without weak anticholinergics regarding high exposure (aOR 1.71 [1.55-1.87] vs. 1.60 [1.38-1.86]). However, the odds ratios for low, intermediate, and high vs. minimal cumulative exposure increased from 1.06-1.22 to 1.24-1.41 when the anticholinergic burden was measured using ACB excluding weak anticholinergics. No substantial changes were found in the association of anticholinergic exposure with the incidence of dementia after measuring drug exposure 5-10 years prior to the index date. This led to small reductions in the associations.

\section{Discussion}

This study confirmed that cumulative anticholinergic exposure is associated with the incidence of dementia. Even though the direct comparison is not possible owing to different study designs and methods, this finding supports the results of previous studies $[8,9,11]$.

Additionally, we showed the significant dose-response relationship of anticholinergic burden measured using $\mathrm{KABS}$, compared to that using $\mathrm{ACB}$, with incident dementia which suggests $\mathrm{KABS}$, the anticholinergic burden scale specific to the Korean population, can be used as a 
Table 2 Prevalence of anticholinergic burden score measured using KABS and ACB with and without including weak anticholinergics

\begin{tabular}{|c|c|c|c|c|c|c|c|c|}
\hline & \multicolumn{4}{|c|}{ Non-dementia $(N=57,712)$} & \multicolumn{4}{|c|}{ Dementia $(N=28,864)$} \\
\hline & KABS & KABS-1 & $\mathrm{ACB}$ & ACB-1 & KABS & KABS-1 & ACB & ACB-1 \\
\hline \multicolumn{9}{|c|}{ Anticholinergic exposure during 2-10 year before index year } \\
\hline Minimal $(<0.25)$ & $\begin{array}{l}29,280 \\
(50.7 \%)\end{array}$ & $\begin{array}{l}38,227 \\
(66.2 \%)\end{array}$ & $\begin{array}{l}23,890 \\
(41.4 \%)\end{array}$ & $\begin{array}{l}48,142 \\
(83.4 \%)\end{array}$ & $\begin{array}{l}13,347 \\
(46.2 \%)\end{array}$ & $\begin{array}{l}17,739 \\
(61.5 \%)\end{array}$ & $\begin{array}{l}11,502 \\
(39.9 \%)\end{array}$ & $\begin{array}{l}23,031 \\
(79.8 \%)\end{array}$ \\
\hline Low $(0.25-1)$ & $\begin{array}{l}22,060 \\
(38.2 \%)\end{array}$ & $\begin{array}{l}16,555 \\
(28.7 \%)\end{array}$ & $\begin{array}{l}24,785 \\
(43.0 \%)\end{array}$ & $\begin{array}{l}8,176 \\
(14.2 \%)\end{array}$ & $\begin{array}{l}11,556 \\
(40.0 \%)\end{array}$ & $\begin{array}{l}9,167 \\
(31.8 \%)\end{array}$ & $\begin{array}{l}12,433 \\
(43.1 \%)\end{array}$ & $\begin{array}{l}4,854 \\
(16.8 \%)\end{array}$ \\
\hline Intermediate (1-2) & $\begin{array}{l}5,136 \\
(8.9 \%)\end{array}$ & $\begin{array}{l}2,488 \\
(4.3 \%)\end{array}$ & $\begin{array}{l}7,447 \\
(12.9 \%)\end{array}$ & $\begin{array}{l}1,188 \\
(2.1 \%)\end{array}$ & $\begin{array}{l}3,045 \\
(10.6 \%)\end{array}$ & $\begin{array}{l}1,630 \\
(5.6 \%)\end{array}$ & $\begin{array}{l}3,954 \\
(13.7 \%)\end{array}$ & $\begin{array}{l}830 \\
(2.9 \%)\end{array}$ \\
\hline High $(\geq 2)$ & $\begin{array}{l}1236 \\
(2.1 \%)\end{array}$ & $\begin{array}{l}442 \\
(0.8 \%)\end{array}$ & $\begin{array}{l}1590 \\
(2.8 \%)\end{array}$ & $\begin{array}{l}206 \\
(0.4 \%)\end{array}$ & $\begin{array}{l}916 \\
(3.2 \%)\end{array}$ & $\begin{array}{l}328 \\
(1.1 \%)\end{array}$ & $\begin{array}{l}975 \\
(3.4 \%)\end{array}$ & $\begin{array}{l}149 \\
(0.5 \%)\end{array}$ \\
\hline \multicolumn{9}{|c|}{ Anticholinergic exposure during 5-10 year before index year } \\
\hline Minimal $(<0.25)$ & $\begin{array}{l}32,424 \\
(56.2 \%)\end{array}$ & $\begin{array}{l}40,272 \\
(69.8 \%)\end{array}$ & $\begin{array}{l}27,297 \\
(47.3 \%)\end{array}$ & $\begin{array}{l}50,009 \\
(86.7 \%)\end{array}$ & $\begin{array}{l}15,283 \\
(53.0 \%)\end{array}$ & $\begin{array}{l}19,174 \\
(66.4 \%)\end{array}$ & $\begin{array}{l}13,566 \\
(47.0 \%)\end{array}$ & $\begin{array}{l}24,226 \\
(83.9 \%)\end{array}$ \\
\hline Low $(0.25-1)$ & $\begin{array}{l}19,959 \\
(34.6 \%)\end{array}$ & $\begin{array}{l}14,903 \\
(25.8 \%)\end{array}$ & $\begin{array}{l}22,432 \\
(38.9 \%)\end{array}$ & $\begin{array}{l}6,662 \\
(11.5 \%)\end{array}$ & $\begin{array}{l}10,389 \\
(36.0 \%)\end{array}$ & $\begin{array}{l}8,093 \\
(28.0 \%)\end{array}$ & $\begin{array}{l}11,105 \\
(38.5 \%)\end{array}$ & $\begin{array}{l}3,937 \\
(13.6 \%)\end{array}$ \\
\hline Intermediate (1-2) & $\begin{array}{l}4,263 \\
(7.4 \%)\end{array}$ & $\begin{array}{l}2128 \\
(3.7 \%)\end{array}$ & $\begin{array}{l}6,539 \\
(11.3 \%)\end{array}$ & $\begin{array}{l}862 \\
(1.5 \%)\end{array}$ & $\begin{array}{l}2,482 \\
(8.6 \%)\end{array}$ & $\begin{array}{l}1,333 \\
(4.6 \%)\end{array}$ & $\begin{array}{l}3,372 \\
(11.7 \%)\end{array}$ & $\begin{array}{l}588 \\
(2.0 \%)\end{array}$ \\
\hline High $(\geq 2)$ & $\begin{array}{l}1,066 \\
(1.9 \%)\end{array}$ & $\begin{array}{l}409 \\
(0.7 \%)\end{array}$ & $\begin{array}{l}1,444 \\
(2.5 \%)\end{array}$ & $\begin{array}{l}179 \\
(0.3 \%)\end{array}$ & $\begin{array}{l}710 \\
(2.5 \%)\end{array}$ & $\begin{array}{l}264 \\
(0.9 \%)\end{array}$ & $\begin{array}{l}821 \\
(2.8 \%)\end{array}$ & $\begin{array}{l}113 \\
(0.4 \%)\end{array}$ \\
\hline
\end{tabular}

KABS Korean anticholinergic burden scale, KABS-1 Korean anticholinergic burden scale without medications of score 1, $A C B$ Anticholinergic cognitive burden, $A C B$ -

1 Anticholinergic cognitive burden without medications of score 1

validated tool to predict the risk of dementia, at least among the older Korean population.

While most previous studies measured anticholinergic burden with the use of strong anticholinergics $[2,7,8$, 11], we measured anticholinergic burden using the scales that ranked the anticholinergic potency as a score for each agent including weak anticholinergics. According to our findings, compared with minimal anticholinergic use, an average daily anticholinergic score of 2 or higher was associated with a 1.71-fold increase in the odds of incident dementia.

A retrospective cohort study which examined the anticholinergic burden with incident dementia as one of the adverse clinical outcomes using the Taiwan national claims database [10] suggested ACB shows good dose response relationship with incident dementia. Compared with the present study, that study showed greater associations (aOR 3.13-10.01 in 65-74 years, aOR 2.76-7.44 in 75-84 years). However, they did not exclude the anticholinergic used for the treatment of prodromal symptoms of dementia. A large community-based longitudinal cohort study conducted by Gray et al. [8] showed that strong anticholinergics used for more than 3 years with mean $7.3 \pm 4.8$ years of follow up period was associated with increased risk of dementia (hazard ratio, 1.54 (95\% CI, 1.21-1.96).

We also showed the negative impact of including weak anticholinergics $($ score $=1)$ on the magnitude of association with incident dementia when the $\mathrm{ACB}$ scale was used. These results were consistent with the findings from previous studies $[9,11]$, where no relationship or no dose response relationship were observed between exposure to a greater number of drugs with an ACB score 1 and incident dementia. However, this finding was not observed when the burden was measured using KABS. This might be explained by the difference in medication lists of weak anticholinergics between $\mathrm{KABS}$ and $\mathrm{ACB}$. In the $\mathrm{ACB}$ scale, cardiovascular agents such as hydrochlorothiazide, atenolol, nifedipine, and isosorbide are included as weak anticholinergics, which were determined as score 0 in the KABS by expert consensus after a comprehensive review of other existing scales [6]. This finding was consistent with that from a previous study that showed a slightly negative association of cardiovascular anticholinergic agents with dementia [9]. Based on these findings, the recommendation of reduced use of these cardiovascular agents to reduce the anticholinergic burden to prevent dementia should be deferred until further research. The significant differences in the prevalence and the association with clinical outcome of anticholinergic exposure according to the scales were consistent with the results from a previous study [14].

A sensitivity analysis that investigated the association after excluding most recent 4 years prior to the index date to minimize the effect of using anticholinergics for the prodromal syndrome of dementia showed the identical trend in the effect of anticholinergic burden to the onset of dementia. Thus, we confirmed the robustness 
Table 3 Top 20 medications that contributed to the anticholinergic burden score in dementia patients with high exposure prior to 2-10 years of dementia according to the scales

\begin{tabular}{|c|c|c|c|c|c|c|c|}
\hline \multirow{3}{*}{$\begin{array}{l}\text { Drug } \\
\text { chlorpheniramine }{ }^{a, b}\end{array}$} & \multicolumn{3}{|c|}{ Total $(\boldsymbol{N}=1,324)$} & \multicolumn{2}{|c|}{ KABS $(\boldsymbol{N}=916)$} & \multicolumn{2}{|c|}{$\mathrm{ACB}(\boldsymbol{N}=975)$} \\
\hline & \multicolumn{2}{|c|}{$\begin{array}{l}\text { Number of } \\
\text { patients (\%) }\end{array}$} & \multirow{2}{*}{$\begin{array}{l}\text { Average DDD per } \\
\text { patient per year } \\
17\end{array}$} & \multirow{2}{*}{$\begin{array}{l}\text { score } \\
3\end{array}$} & \multirow{2}{*}{$\begin{array}{l}\text { Contribution to } \\
\text { high exposure }(\%) \\
5.8\end{array}$} & \multirow{2}{*}{$\begin{array}{l}\text { score } \\
3\end{array}$} & \multirow{2}{*}{$\begin{array}{l}\text { Contribution to } \\
\text { high exposure }(\% \\
5.2\end{array}$} \\
\hline & 1,297 & $(98.0)$ & & & & & \\
\hline tramadol $^{a}$ & 1,262 & $(95.3)$ & 9.2 & 2 & 2.3 & 0 & 0 \\
\hline cimetidine $^{a, b}$ & 1,260 & $(95.2)$ & 46.7 & 2 & 11.6 & 1 & 4.0 \\
\hline diazepamma, b & 1,198 & $(90.5))$ & 34.8 & 1 & 4.2 & 1 & 3.4 \\
\hline ranitidine $e^{a, b}$ & 1,150 & $(86.9)$ & 28.6 & 1 & 3.1 & 1 & 3.0 \\
\hline hydrochlorothiazide ${ }^{b}$ & 974 & (73.6) & 80.2 & 0 & 0 & 1 & 10.1 \\
\hline alprazolamª, b & 921 & $(69.6)$ & 32.5 & 1 & 4.1 & 1 & 3.2 \\
\hline dimenhydrinate $e^{a, b}$ & 869 & $(65.6)$ & 33.3 & 3 & 11.3 & 3 & 11.7 \\
\hline amitriptyline $^{a, b}$ & 727 & $(54.9)$ & 10.9 & 3 & 3.8 & 3 & 3.4 \\
\hline theophylline $e^{a, b}$ & 664 & $(50.2)$ & 13.8 & 1 & 1.5 & 1 & 1.5 \\
\hline furosemide $^{a, b}$ & 606 & $(45.8)$ & 39.5 & 1 & 4.3 & 1 & 5.0 \\
\hline atenolol $^{b}$ & 549 & $(41.5)$ & 33 & 0 & 0 & 1 & 4.3 \\
\hline lorazepam ${ }^{a}$ & 515 & $(38.9)$ & 11.9 & 1 & 1.5 & 0 & 0 \\
\hline nifedipine $^{b}$ & 459 & $(34.7)$ & 38 & 0 & 0 & 1 & 5.2 \\
\hline triazolam $^{a}$ & 454 & $(34.3)$ & 15.8 & 1 & 2.1 & 0 & 0 \\
\hline octylonium bromide & 451 & $(34.1)$ & 4.5 & 3 & 1.8 & 0 & 0 \\
\hline tolterodine $\mathrm{e}^{\mathrm{a}, \mathrm{b}}$ & 355 & $(26.8)$ & 7.9 & 3 & 2.7 & 3 & 2.8 \\
\hline propiverine $^{a, b}$ & 342 & $(25.8)$ & 6.3 & 3 & 2.2 & 3 & 2.2 \\
\hline isosorbide $^{b}$ & 290 & $(21.9)$ & 40.2 & 0 & 0 & 1 & 5.4 \\
\hline doxazosin ${ }^{b}$ & 263 & (19.9) & 18.1 & 0 & 0 & 1 & 2.4 \\
\hline digoxin $^{b}$ & 215 & $(16.2)$ & 13.3 & 1 & 1.2 & 1 & 1.7 \\
\hline paroxetine $^{a, b}$ & 209 & $(15.8)$ & 9.3 & 2 & 2.1 & 3 & 3.5 \\
\hline quinupramine $^{a}$ & 188 & $(14.2)$ & 5.1 & 3 & 2.2 & 0 & 0 \\
\hline solifenacin ${ }^{a, b}$ & 174 & (13.1) & 6.1 & 3 & 2.1 & 3 & 2.3 \\
\hline levodopa and decarboxylase inhibitor ${ }^{a}$ & 166 & $(12.5)$ & 12.6 & 1 & 1.8 & 0 & 0 \\
\hline beztropine ${ }^{b}$ & 77 & $(5.8)$ & 3.6 & 3 & 1.4 & 3 & 1.3 \\
\hline amantadine $^{a}$ & 76 & (5.7) & 6.3 & 2 & 1.8 & 2 & 1.1 \\
\hline
\end{tabular}

$D D D$ Defined daily dose, KABS Korean Anticholinergic Burden Scale, $A C B$ Anticholinergic Cognitive Burden

${ }^{a}$ Top 20 medications to contribute to anticholinergic burden in high exposure group with KABS

${ }^{\mathrm{b}}$ Top 20 medications to contribute to anticholinergic burden in high exposure group with ACB

of the correlation between anticholinergic burden and dementia onset. Additionally, this result is similar to that from a previous case-control study by Richardson and colleagues [9]. They categorized exposure using the cumulative DDD and average ACB score. The daily average ACB score of 2 during the prior $5-10$ years in our study corresponds to $1460 \mathrm{DDD}$ of drugs with a score of 3 . They showed weak associations with 1460 DDD of drugs with a score of 1 , which corresponds to the daily average ACB score of 0.7 .

The strengths of this study are 1) we took into account the prescribed dosage and potency of anticholinergics when measuring anticholinergic burden unlike in most previous studies, 2) we analyzed the long-term drug exposure in all participants of a nationally representative large sample with the consideration of reverse causation bias, 3) we considered sedative load other than anticholinergics as a covariate to adjust for the effect of sedatives and medications with sedation as a prominent side effects on incidence of dementia, and 4) we tested the performance of the ACB and KABS scales for the prediction of dementia with or without weak anticholinergics. This was the first attempt to test the influence of including weak anticholinergics in measuring burden using these scales on the prediction of the incidence of dementia. 
Table 4 Adjusted odds ratios for incident dementia according to anticholinergic burden measured using KABS and ACB with and without weak anticholinergics

\begin{tabular}{|c|c|c|c|c|}
\hline & \multicolumn{2}{|c|}{ Including medications with score 1} & \multicolumn{2}{|c|}{ Excluding medications with score 1} \\
\hline & $\begin{array}{l}\text { KABS } \\
\mathrm{aOR}^{\mathrm{a}}(95 \% \mathrm{Cl})\end{array}$ & $\begin{array}{l}\text { ACB } \\
\text { aOR }^{\mathrm{a}}(95 \% \mathrm{Cl})\end{array}$ & $\begin{array}{l}\text { KABS-1 } \\
\mathrm{aOR}^{\mathrm{a}}(95 \% \mathrm{Cl})\end{array}$ & $\begin{array}{l}\text { ACB-1 } \\
\text { aOR }{ }^{\mathrm{a}}(95 \% \mathrm{Cl})\end{array}$ \\
\hline \multicolumn{5}{|c|}{ Anticholinergic exposure during 2-10 years before index year } \\
\hline Minimal $(<0.25)$ & reference & reference & reference & reference \\
\hline Low $(0.25-1)$ & $1.21(1.17-1.25)$ & $1.06(1.04-1.10)$ & $1.23(1.19-1.28)$ & $1.24(1.19-1.29)$ \\
\hline Intermediate (1-2) & $1.39(1.31-1.46)$ & $1.10(1.04-1.15)$ & $1.45(1.36-1.56)$ & $1.42(1.30-1.56)$ \\
\hline High $(\geq 2)$ & $1.71(1.55-1.87)$ & $1.22(1.12-1.33)$ & $1.60(1.38-1.86)$ & $1.41(1.14-1.75)$ \\
\hline \multicolumn{5}{|c|}{ Anticholinergic exposure during 5-10 years before index year } \\
\hline Minimal $(<0.25)$ & reference & reference & reference & reference \\
\hline Low $(0.25-1)$ & $1.14(1.10-1.18)$ & $1.00(0.96-1.03)$ & $1.17(1.13-1.21)$ & $1.22(1.17-1.28)$ \\
\hline Intermediate (1-2) & $1.27(1.20-1.35)$ & $1.02(0.97-1.08)$ & $1.33(1.24-1.44)$ & $1.38(1.24-1.54)$ \\
\hline High $(\geq 2)$ & $1.44(1.30-1.59)$ & $1.09(0.99-1.19)$ & $1.35(1.15-1.58)$ & $1.23(0.97-1.56)$ \\
\hline
\end{tabular}

aOR Adjusted odds ratio, $C$ C Confidence interval, KABS Korean anticholinergic burden scale, $A C B$ Anticholinergic cognitive burden, KABS-1 Korean anticholinergic burden scale without medications of score 1, $A C B-1$ Anticholinergic cognitive burden without medications of score 1

${ }^{a}$ Adjusted for age, sex, sedative load and comorbid diseases (hypertension, dyslipidemia, heart failure, atrial fibrillation, ischemic heart disease, diabetes mellitus, cerebrovascular disease, Parkinson's disease, depression, anxiety, schizophrenia, bipolar disorder, insomnia, alcohol disease, obesity, substance abuse, and tobacco dependence and use)

There are several limitations to consider when interpreting the results of the present study. First, although we carefully addressed the confounding factors associated with the incidence of dementia with propensity matching and multivariate analysis, we could not consider the other confounding factors such as smoking, alcohol consumption, family history, and educational level that might contribute to the incidence of dementia owing to the nature of data analyzed. Second, we could not consider taking non-prescription anticholinergics such as first-generation antihistamines. Third, the diagnosis of a disease might not be correct owing to the nature of claims data. To reduce the possibilities of misdiagnosis, patients were considered as having the corresponding diseases when the diagnostic codes were presented at least twice. Additionally, the diagnosis of dementia might be missed if the patients did not visit healthcare facilities for the symptoms.

Considering the robust associations between high anticholinergic exposure and incident dementia from the present study consistent with previous studies, it is necessary to provide physicians and clinical pharmacists with a calculated anticholinergic burden score for specific patients. This process has been proven to help reduce the anticholinergic burden [15].

\section{Conclusion}

This study confirmed the findings of previous studies by showing the dose response relationship for cumulative anticholinergic burden measured using the KABS, the anticholinergic burden scale specific for Korean populations, with incident dementia.

\section{Supplementary information}

Supplementary information accompanies this paper at https://doi.org/10. 1186/s12877-020-01671-z.

Additional file 1. Anticholinergic medication list.

Additional file 2. The ICD-10 codes used for analysis.

Additional file 3. List of medication with sedation as a prominent side effects.

\section{Abbreviations}

ACB: Anticholinergic Cognitive Burden scale; ADS: Anticholinergic Drug Scale; aOR: Adjusted odds ratio; ARS: Anticholinergic Risk Scale; Cl: Confidence Interval; DDD: Defined Daily Dose; ICD: International Classification of Diseases; IQR: Inter-quartile range; KABS: Korean version Anticholinergic Burden Scale

\section{Acknowledgements}

Not applicable.

\section{Authors' contributions}

YS and YMA: Conceptualization, Data curation, Formal Analysis, WritingOriginal draft preparation. EH, KJ, SH, and KHC: Methodology, Validation, Writing - Review \& Editing. JYL: Conceptualization, Methodology, Supervision, Writing - Review \& Editing, Funding Acquisition. All authors read and approved the final manuscript.

\section{Funding}

This research was supported by Basic Science Research Program through the National Research Foundation of Korea (NRF) funded by the Ministry of Education (2017R1D1A1B03029528).

\section{Availability of data and materials}

The dataset supporting the conclusions of this article is available from the Korea National Health Insurance Service (KNHIS) Data Sharing Service homepage (https://nhiss.nhis.or.kr/bd/ab/bdaba001cv.do) but restrictions apply to the availability of these data. The KNHIS, the data provider, requires all involved researchers to pledge not to share, release, or review the data with other entities. 


\section{Ethics approval and consent to participate}

This study was approved by the Institutional Review Board of Hanyang University (IRB: HYI-17-007-1). Informed consent was waived because only de-identified information was provided without linkable data elements.

\section{Consent for publication}

Not applicable.

\section{Competing interests}

All of authors declare that have no competing interests.

\section{Author details}

${ }^{1}$ College of Pharmacy and Research Institute of Pharmaceutical Sciences, Seoul National University, 1 Gwanak-ro, Gwanak-gu, Seoul 08826, Republic of Korea. ${ }^{2}$ Department of Pharmacy, Seoul National University Bundang Hospital, 82, Gumi-ro 173 Beon-gil, Bundang-gu, Seongnam-si, Gyeonggi-do 13620, Republic of Korea. ${ }^{3}$ College of Pharmacy, Yeungnam University, 280 Daehak-ro, Gyeongsan-si, Gyeongsangbuk-do 38541, Republic of Korea. ${ }^{4}$ College of Pharmacy, Yonsei Institute for Pharmaceutical Research, Yonsei University, 85 Songdogwahak-ro, Yeonsu-gu, Incheon 21983, Republic of Korea. ${ }^{5}$ College of Pharmacy and Institute of Pharmaceutical Science and Technology, Hanyang University, 55 Hanyangdeahak-ro, Sangnok-gu, Ansan-si, Gyeonggi-do 15588, Republic of Korea. ${ }^{6} \mathrm{College} \mathrm{of} \mathrm{Pharmacy,}$ Sunchon National University, 255 Jungang-ro, Suncheon-si, Jeollanam-do 57922, Republic of Korea.

Received: 11 November 2019

Published online: 29 July 2020

\section{References}

1. Association As. 2018 Alzheimer's disease facts and figures. Alzheimers Dement. 2018;14(3):367-429.

2. Jessen F, Kaduszkiewicz H, Daerr M, Bickel H, Pentzek M, Riedel-Heller S, et al. Anticholinergic drug use and risk for dementia: target for dementia prevention. Eur Arch Psychiatry Clin Neurosci. 2010;260(Suppl 2):S111-5.

3. Fox C, Smith T, Maidment I, Chan W-Y, Bua N, Myint PK, et al. Effect of medications with anti-cholinergic properties on cognitive function, delirium, physical function and mortality: a systematic review. Age Ageing. 2014;43(5): 604-15

4. Salahudeen MS, Duffull SB, Nishtala PS. Anticholinergic burden quantified by anticholinergic risk scales and adverse outcomes in older people: a systematic review. BMC Geriatr. 2015;15(1):31.

5. Mate KE, Kerr KP, Pond D, Williams EJ, Marley J, Disler P, et al. Impact of multiple low-level anticholinergic medications on anticholinergic load of community-dwelling elderly with and without dementia. Drugs Aging 2015;32(2):159-67.

6. Jun K, Hwang S, Ah YM, Suh Y, Lee JY. Development of an anticholinergic burden scale specific for Korean older adults. Geriatr Gerontol Int. 2019; 19(7):628-34.

7. Carriere I, Fourrier-Reglat A, Dartigues JF, Rouaud O, Pasquier F, Ritchie K, et al. Drugs with anticholinergic properties, cognitive decline, and dementia in an elderly general population: the 3-city study. Arch Intern Med. 2009; 169(14):1317-24.

8. Gray SL, Anderson ML, Dublin S, Hanlon JT, Hubbard R, Walker R, et al. Cumulative use of strong anticholinergics and incident dementia: a prospective cohort study. JAMA Intern Med. 2015;175(3):401-7.

9. Richardson K, Fox C, Maidment I, Steel N, Loke YK, Arthur A, et al. Anticholinergic drugs and risk of dementia: case-control study. BMJ. 2018; 361:k1315

10. Hsu WH, Wen YW, Chen LK, Hsiao FY. Comparative associations between measures of anti-cholinergic burden and adverse clinical outcomes. Ann Fam Med. 2017;15(6):561-9.

11. Joung Kl, Kim S, Cho YH, Cho SI. Association of Anticholinergic use with incidence of Alzheimer's disease: population-based cohort study. Sci Rep. 2019;9(1):6802

12. Andre L, Gallini A, Montastruc F, Coley N, Montastruc JL, Vellas B, et al. Anticholinergic exposure and cognitive decline in older adults: effect of anticholinergic exposure definitions in a 3-year analysis of the multidomain Alzheimer preventive trial (MAPT) study. Br J Clin Pharmacol. 2019;85(1):71-99.
13. Kim H, Chun HW, Kim S, Coh BY, Kwon OJ, Moon YH. Longitudinal studybased dementia prediction for public health. Int J Environ Res Public health. 2017;14(9):983

14. Turro-Garriga O, Calvo-Perxas L, Vilalta-Franch J, Blanco-Silvente L, Castells X, Capella $D$, et al. Measuring anticholinergic exposure in patients with dementia: a comparative study of nine anticholinergic risk scales. Int J Geriatr Psychiatry. 2018;33(5):710-7.

15. Tay HS, Soiza RL, Mangoni AA. Minimizing anticholinergic drug prescribing in older hospitalized patients: a full audit cycle. Ther Adv Drug Saf. 2014;5(3): $121-8$.

\section{Publisher's Note}

Springer Nature remains neutral with regard to jurisdictional claims in published maps and institutional affiliations.
Ready to submit your research? Choose BMC and benefit from:

- fast, convenient online submission

- thorough peer review by experienced researchers in your field

- rapid publication on acceptance

- support for research data, including large and complex data types

- gold Open Access which fosters wider collaboration and increased citations

- maximum visibility for your research: over $100 \mathrm{M}$ website views per year

At $\mathrm{BMC}$, research is always in progress.

Learn more biomedcentral.com/submissions 